Check for updates

London, UK

Cite this as: BMJ 2020;369:m2472 http://dx.doi.org/10.1136/bmj.m2472 Published: 19 June 2020

\section{Covid-19: UK drops its own contact tracing app to switch to Apple and Google model}

\author{
Jacqui Wise
}

The NHS has abandoned its plans to develop its own centralised app for contact tracing in favour of developing a version based on technology provided by Google and Apple.

The major U turn is an embarrassment for the government as the app was originally designed to be a key component of its test, track, and trace programme.

Ministers had wanted a centralised version of the technology in which anonymised data from people who reported covid-19 symptoms could be held on a NHS database. In the decentralised model, no data are held in a single official database. Earlier this week, Italy and Germany launched apps based on the Google-Apple Model.

However, the NHS app, which has been tested in the Isle of Wight, only recognised 4\% of Apple phones and $75 \%$ of Google's Android devices. This is because the design of Apple's operating system for iPhones means that apps go to sleep when they are not being used and cannot be activated by Bluetooth.

The government said they had been testing both systems over the past month and found that the Apple-Google model recognised $99 \%$ of both Android phones and iPhones. This model does, however, have problems distinguishing between whether someone is one metre or three metres away.

At the government's daily pandemic briefing, health secretary Matt Hancock said, “As it stands, our app won't work, because Apple won't change their system. But it can measure distance. And their app can't measure distance well enough to a standard we are satisfied with." He added, "We will share our algorithm and the work we have done on distance calculation and combine that with their work, to deliver a new solution."

Hancock would not put a date on when the new app will be launched, but it will not be ready until autumn at the earliest. And the product may not involve contact tracing at that time and may be limited to enabling users to report symptoms, access advice, and order a test.

Hancock said, "In the meantime, the test and trace system, based on good old fashioned human contact tracing is working well, identifying local outbreaks and helping us control the virus.” The latest figures showed that a quarter of people who tested positive for covid-19 in the test and trace scheme's second week could not be reached.

In a statement, the Independent Scientific Advisory Group for Emergencies said it was "deeply concerned about the current government contact tracing system which is not fit for purpose.”
Chris Hopson, chief executive of NHS Providers, described the announcement about the app as disappointing. "This is a setback in delivering a world beating test and trace system, in which an effective app would play a valuable role.” He added, “This episode presents yet another example of the dangers of overpromising and underdelivering." 